\title{
Assessment of English Versions of Product Introductions of Alcoholic Drinks
}

\author{
From Functionalist Approaches
}

\author{
Xiuqin Hong \\ Department of College English \\ Xiamen University Tan Kah Kee College \\ Zhangzhou, China
}

\begin{abstract}
With the help of Nord's model for translationoriented text analysis, the author finds out how the Chinese and English product introductions of alcoholic drinks differ after conducting the analysis of the intratextual and extratextual factors in the Chinese product introductions and the parallel English product introductions. On the one hand, the Skopostheorie guides the assessment, from an overall point of view, of the English versions of the Chinese product introductions; the findings in the text analysis of both Chinese and English product introductions of alcoholic drinks, on the other, stands as the framework of reference against which a large part of the assessment is done. Improvements of the poor translation are accordingly suggested in light of the functionalist approaches.
\end{abstract}

Keywords-assessment; product introductions of alcoholic drinks; functionalist approaches; Skopostheorie

\section{INTRODUCTION}

To survive and grow in the competitive economic "global village", many Chinese enterprises are developing the overseas market where a bilingual advertising of their products is needed to win and keep the foreign customers, while English is the most popular language adopted. Under the circumstances, it is rather encouraging than surprising to find that some of the Chinese alcohol producers, especially export-oriented ones, have their websites in both Chinese and English.

Product introductions, as one of the important components of the content on the websites, are meant to familiarize potential customers with the products by introducing them to the characteristics or the quality of the products with images and words that appeal. However, there remain a lot of problems at different levels when we take a close look at the English translations of the product introductions on these websites. They will, to some extent, affect the sales volume of the products, if the translations provide potential customers with the wrong information or convey the information improperly. The current situation in this area strikes the author as being the one that necessitates the study of the Chinese-English translation of product introductions of alcoholic drinks.
This paper focuses on the Chinese-English translation (hereafter referred to as the C-E translation) of the product introductions of alcoholic drinks on the websites of some famous brands, aiming to find ways to assess the translation under the guidance of "Skopostheorie", which proves to be workable in justifying a translated text in that product introductions, when translated into the target language, may remain the same in terms of the function to persuade the readers to buy the products.

\section{LITERATURE REVIEW}

The recent decade witnesses a lot of work done in the area of advertisement translation, either at or beyond the linguistic level. In particular, many scholars have chosen the functionalist approaches in discussing the translation strategies, observing that the theory of Skopostheorie is conducive to realizing the purpose and the intended functions of the advertisements. In the process, another essential aspect of advertisements is involved, i.e. text type and text functions. The translation theories and practice tend to shift from the discussion about "equivalence" between source texts and target texts to the realization of necessary language adaptation in the target texts in the light of the translation purposes and the text functions. (Ping, 2002)

Liu Jiafeng (2002) discusses the characteristics of alcoholic drink advertisements. The description of the properties of the drinks and the advertisements (or different parts of an advertisement) themselves require different styles of language. In the headlines or slogans of the advertisements poetic language is usually adopted to arouse the readers' interest. The language is concise and simple. Besides, the technical terms of the processing and quality of the alcoholic products which add to the difficulty of translation appear. This is one of the differences that tell apart advertisements of alcoholic drinks and those of others. Zou Jianling (2012) put in contrast Chinese and English product introductions in both language style and market orientation. Chinese product introductions prefer fourcharacter descriptive phrases like “科学工艺”(advanced techniques) and “品味纯正” (authentic taste), while the English product introductions are more objective and direct in relating to readers with basic information. 
In dealing with the language differences, after a comparative analysis of the two versions of Moutai (茅台酒) advertisements, Yan and Zhang (2006: 67, 70) suggest adaptation and free translation in the light of Skopostheorie in order to trigger the readers' desire to buy products.

When discussing the Chinese-English translation strategies, most of the authors come up with different parts of advertisements, covering headline, slogan and trademark. In addition, though the cases analyzed mostly at the linguistic level involve looking into the problems covering company profiles, tourist literature, instructions, and product introductions, few elaborate on one specific area, say, product introductions, or even fewer on the evaluation of the Chinese-English translation of the product introductions of alcoholic drinks.

\section{FUNCTION-ORIENTED APPROACHES AS THE THEORETICAL FRAMEWORK}

\section{A. A Translation-oriented Model of Text Functions by Nord}

Bühler's 'organon model' serves as the starting point for Nord's translation-oriented model based on text functions, basically referential, expressive, appellative functions. The appellative function is directed at the readers' sensitivity and disposition to act. "If we want to make someone buy a particular product, we appeal to their real or imaged needs, describing these qualities of the product that are presumed to have positive values in the receivers' value system. (Nord, 2001:42)"

\section{B. Skopostheorie}

The Skopos theory, developed by the "German school" in the late 1970s, reflects "a general shift from predominantly linguistic and rather formal translation theories to a more functional and socio-cultural oriented concept of translation" ( $\mathrm{Li}$ et al, 2005: 93). According to Skopostheorie the top-ranking rule for any translation is the 'Skopos rule' that reads as follows: translate/interpret/speak/write in a way that enables your text/translation to function in the situation in which it is used with the people who want to use it and precisely in the way they want it to function. (Nord, 2001:29) Another important rule of Skopostheorie is called "coherence rule", according to which the target text must be sufficiently coherent to allow the intended users to comprehend it, given their assumed background knowledge and situational circumstances ( $\mathrm{Li}$ et al, 2005:94). The third rule is referred to as 'fidelity rule', which reflects the relationship between the target text and its corresponding source text: inter-textual coherence. The translation Skopos or the translator's interpretation of the source text decides the form it will take.

\section{The Factors of Source-text Analysis}

The factors of the communicative situation in which the source text is used are called "extratextual factors" by Nord (2006: 40), as opposed to the "intratextual factors" that relate to the text itself, including its non-verbal factors.
Extratextual factors include the sender or the producer of the text, the sender's intention, the audience the text is directed at, the medium or channel, the place and time of text production and text reception, the motive for communication and finally the function the text is supposed to achieve.

Intratextual factors are analyzed by looking into the subject matter the text deals with, the content presented in the text, the presupposed knowledge, the composition or construction of the text, the non-linguistic or paralinguistic elements accompanying the text, the lexis and syntactic structures of the text and etc.

\section{The Way the Theoretical Framework is Applied in the Study}

Once the text types are determined, it is necessary to evaluate the quality of the translation by judging how well it is adequate to the requirements laid down by the translation brief backed up by the top-ranking Skopos and whether the translation realizes the functional equivalence between the source and target texts. Both "intratextual coherence" and "intertextual coherence" are unarguably to be taken into account in the assessment of the quality of the translation.

\section{EXTRATEXTUAL AND INTRATEXTUAL FACTORS}

\section{A. Extratextual Factors in the Chinese and English Product Introductions of Alcoholic Drinks}

The Chinese and English product introductions of alcoholic drinks drawn on here, whatever intratextual factors might be involved, are consistent in the area of extratextual factors in that the introductions share all the same factors as mentioned above. Therefore a general discussion instead of individual analysis will be made about the samples.

The sender, apparently, is the producer of alcoholic drinks who expects potential customers with the help of product introductions that provide information about the product and appeal to the audience's purchasing desire (where the sender's intention lies). The audience in question turns out to be a large and non-specific audience who ever has access to the internet (the medium in which the product introductions are communicated). As for the motive of the communication, the sender's intention may help explain what it is: to promote and sell the product. These known factors lead to the answer to what functions the text can perform: the informative function performed by the text where the audience is meant to know as much as the sender intends and/or the vocative function of the text calling upon the audience to buy the product.

\section{B. Intratextual Factors in the Chinese Product Introductions of Alcoholic Drinks}

In terms of the content, such things as ingredients distillation technique or process, history and honors a drink is given are features common to Chinese product introductions. Some may include the part of look, taste and smell people may enjoy when the wine or liquor is served. 
As far as lexis is concerned, the words used in the texts are of two groups, informative and non-informative, the latter of which may involve some subcategories, aesthetic and appellative, for example. Typical examples can be cited of the common adjectives that frequently appear in the description of the look, taste and smell of the alcoholic drinks. Antithesis or parallelism can be found in the clauses of the sentences, which is more aesthetic and appellative than informative.

\section{Intratextual factors in the English product introductions}

English product introductions most often cover the following aspects of the content: history of the brand, tasting notes (smell, color or taste of the drink) and ingredients, the blending of the drink.

The lexis part is approached from the functions words play. Different from the content and composition part of the Chinese and English sample texts where may be found many differences on the two sides, the lexis part of the English sample texts share some common features with the Chinese ones. The lexical items that fit in with the following two categories can unmistakably be found in all the four sample texts: words that impart information and words that serve as proud boast. However, the English product introductions usually do not give as much space to stressing the second category of the above two as the Chinese ones do. In particular, in the English product introductions words serving as proud boast are mainly about something more substantial and convincing in terms of the content the words convey. One of the important facts that set these English texts apart from the Chinese ones is that form of address. Judging from the tone, the English texts are more conversational than their Chinese counterparts thanks to the use of pronouns "you" and "we". It is, as a matter of fact, an advertising strategy in winning the customer through language use.

\section{ADEQUATE OR INADEQUATE TRANSLATION AND IMPROVEMENT GUIDED BY THE FUNCTIONALIST APPROACHES}

A particular expression or utterance is not inadequate in itself; instead, it only becomes inadequate when it fails to achieve the communicative function it was supposed to realize with regard to the translation brief. Anything that obstructs the achievement of this purpose is a translation error. For functionalism, the notion of translation error must be defined in terms of the purpose of the translation process or product. (Nord, 2001:73)

In the following sample texts, either adequate or inadequate, the translation will be put against the background of functionalism.

\section{A. Sample Text 1}

董酒典型风格的内涵, 十分丰富, 据有关文献报道, 董酒含各种 酸、酯、醇等微量成份达百余种, 现还有数十种未被认识。经我公司 与贵州省轻工科研所合作初步探明, 董酒香味成份与其他名酒不一 样, 具有”三高一低” 的特点, 丁酸乙酯, 高级醇及总酸含量较高, 是其他名酒的 3-5、2-3 倍, 乳酸乙脂含量则是其他名酒的二分之一以 下，”酯香、醇香、药香” 是构成董酒香型的几个重要方面。
董酒舒适的药香与近百味中草药参与小曲、大曲的制作有密切关 系, 在这些药材中, 有我国著名的八大香料药, 还有相当一部分名贵 中草药。如虫草、鹿胶、龟胶、杜仲、枸杞、黄花、北辛等。

由于董酒的三独特（工艺、风格、香气组成比），1959 年即被评 为贵州名酒。

1963 年在全国第二届评酒会上, 被评为中国名酒, 跨入中国八大 名酒行业，荣获金质奖。

1979 年在全国第三届评酒会上, 以” 其它香型”之首, 再次评为 中国名酒，荣获名酒证书。 奖。

1984 年在全国第四届评酒会上, 第三次评为中国名酒, 荣获金质

1989 年，在全国第五届评酒会上，董酒第四次被评为中国名酒， 荣获金质奖。

1959 年起董酒历年被评为贵州名酒, 轻工部优质产品。1 984 年获 轻工出口产品金奖，中国首届文化节中国文化名酒称号，首届中国食 品博览会金奖。

1977 年起董酒出口试销, 口感反映良好。从此出口创汇逐年增 加，现已远销东南亚、日本、加拿大、美国等地区和国家，西欧一些 国家也纷纷要求经销。港澳同胞称它为” 思乡酒” “多情酒” , 外国 朋友称它为”友谊酒”, ”典雅酒”。 (Source:http://www.dongjiu.net.cn/newEbiz1/EbizPortalFG/ portal/html/GeneralContentShow1.html)

Dongjiu Liquor adopts high quality jowar as its raw material and the underground spring of Shuikou Temple, which is $8 \mathrm{~km}$ away from the factory west, as its brewery water, it is produced through unique technology and process. It is appraised to be crystal clear, rich and pleasing taste with remaining flavor.

Dongjiu Liquor is different with the liquor type of sauce, strong, clear and rice, it has its unique style for its pleasing herb taste and sourish taste. According to the opinion of the state liquor tasting committee, Dongjiu liquor is chosen as the representative of "other fragrance type". In order to protect this famous traditional product, the Ministry of Light Industry listed Dongjiu Liquor technology and receipt in the confidential items of science and technology at the grade of "confidential" in 1983, and in 1996 the National Administration for Protection of State Secrets restated that this item was state secret and no publicity was permitted to leak the secret.

Dongjiu Liquor has rich content. It is recorded in some literature that Dongjiu liquor contains over one hundred of micro ingredients of a variety of acid, ester and alcohol, now there are still tens of ingredients unknown. Our cooperative research with Guizhou Scientific Research Institute of Light Industry has proved that the flavour ingredients contained in Dongjiu liquor are different with that in other famous liquors, and it feature high content of ethyl butyrate, higher alcohol and total acid, which are 3-5, 2-3 times than that of other famous liquors, its Ethyl lactate content is only $1 / 2$ or less of the latter. "Aromatic ester, alcohol and medicine" contributes to the flavor of Dongjiu liquor.

Dongjiu Liquor's pleasing herb flavour has a close relation with the involvement of near one hundred Chinese herbs in the production of distiller's yeasts. Among these medicinal materials there are China's eight famous spice 
herbs and certain amount of famous and precious Chinese herbal medicine, such as worm grass, deer gelatin, tortoise gelatin, eucommia bark, eucommia bark, Chinese wolfberry, milk vetch, etc.

Owing to the three features (technology, style and fragrance ratio) of Dongjiu liquor; it was chosen as Guizhou Famous Liquor in 1959.

In 1963, it was chosen as China Famous Liquor in the second session National Liquor Festival and listed in China's eight top liquors with a golden medal obtained.

In 1979, it was chosen as China Famous Liquor in the third session National Liquor Festival as the No.1 of "other odor type" with a famous liquor certificate obtained.

In 1984, it was chosen as China Famous Liquor for the third time with a golden medal obtained in the fourth session National Liquor Festival.

In 1989, it was chosen as China Famous Liquor for the fourth time with a golden medal obtained in the fifth session National Liquor Festival.

Dongjiu liquor has been chosen as Guizhou Famous Liquor and Quality Product of the Ministry of Light Industry for years since 1959 .

In 1984 it was awarded the golden award of export product by the Ministry of Light Industry, won the title of China's Culture Liquor in China's first session Culture Festival and the golden award of the first session China Foodstuff Exposition.

In 1977, Dongjiu Liquor began to be exported for trial sales and was appraised for good taste. From then on, its export has increased with years, now it has been sold to Southeast Asia, Japan, Canada and USA, etc., some Western Europe countries also hope to sell our products. HongkongMacau sibling call it "homesick liquor" or "emotion liquor", while foreign friends call it "friendship liquor" or "elegance liquor".

(Source:http://www.dongjiu.net.cn/newEbiz1/EbizPortal FG/portal/html/GeneralContentShow1.html)

1) Translation criticism: The Chinese original covers many things in the content part and is more than ten paragraphs long. As a product introduction of alcoholic drinks aiming at the domestic customer, the lengthy text seems acceptable though it may risk losing him. It is crystal clear that the target text should be more concise and focused and, therefore, the original text should be adjusted in terms of both content.

The macrostructure of the translation above, the macrostructural units such as paragraphs (formal structure) or beginning and end (functional structure), are found to be exactly the same as those of the original. The English version can be viewed as one out of a word-for-word, sentence-forsentence procedure. The Chinese reader may have no difficulty understanding what there is as content and how it is laid out, but the target reader, that is, the native speaker of English, will now and then feel at loss what the passage is about and why it appears in the way as it is, if the target text preserves every sentence in the same way the original does.

a) Refocus the content: This exceptionally long introduction covers ingredients or materials, distillation technique, look, taste and smell, information about the "unique fragrance type" and lastly a list of honors and prizes it has ever earned. However, the problem is that the translation seems to have focused on nothing by reproducing the original sentence by sentence.

As far as the distillation technique of the liquor is concerned, the unique technique claimed in the original will lose many of the reader if the translation drags on in the details, for the terms seem too professional for the average reader. As concluded in the previous part, few of the English product introductions of alcoholic drinks go so far as to try the professional wine-making terms on their average reader. It is appropriate to simplify the complex process and make it one simple sentence "it is produced through unique technology and process". The same is true of the case with the part of tasting notes, including smell, look and taste of the liquor. Therefore the first paragraph may be successfully transferred into the target language by taking into account the target reader's expectation.

The original text tries to impress on the reader the unique type of fragrance of the liquor resulting from its special content. However, it is perhaps unnecessary to deliberate on the details about the content which turns out to be beyond the ken of the target reader. When it comes to the Chinese herbs, they work for the Chinese reader who is familiar with the traditional herbal medicine. However, for the western reader, listing the names of the Chinese herbs will not add to their understanding of the extraordinary effects the liquor possesses. The information that involves presuppositions or background knowledge will not necessarily call for details, for usually the average target reader expects no more than the major aspects of the information from a product introduction of alcoholic drinks. As in the case in point, the displaying of the names of the Chinese herbs is next to no use to the target reader and become redundant (for the majority of the overseas audience might not be familiar with the specifics of those Chinese herbs despite the fact that they may have been amazed by the magical medical effects).

Honors and prizes prove to be an important part of product introductions of alcoholic drinks as the previous analysis of all those Chinese texts indicates. However, it is worth noting that in the English parallel texts, few of them cover honors and prizes, let alone the translator devoting so much space to the glorious prize-winning history. This part of content contributes to the length of the text in question by listing every honor and prize the liquor has ever won, which goes against the culture-specific conventions of the target language. As analyzed and concluded in the previous chapter, most English parallel texts resort to conversational tones trying to bring the drink closer to the personal lives of the reader, rather than boast about how many prizes it was awarded. Though it will not be necessary and important to have all the information about the honors and prizes deleted, 
some reduction or reorganization will better serve the intended purpose.

b) Readjust the composition: In the original different things are arranged in this way: ingredients or materials, distillation technique, tasting notes appear first (all covered in the first paragraph) to be followed by the claimed unique type of fragrance, the rich content or the microelements and Chinese herbs adopted (the focus of the content); and, last but not least, honors and prizes the liquor is awarded.

The organization of the content in the original may leave the Chinese reader no problems in understanding and appreciating the product, but the rigid adherence in the English rendering to the original in the macrostructure will absolutely pose trouble for the target reader with a different picture in their mind's eye where things are or should be put. It will be easier and clearer for the target reader to grasp the focus of the product if the translator arranges the translation in the following order: ingredients and tasting notes, special type of fragrance and its contributing factors (the focus of the introduction) and simplified version of honors and prizes. Among the contributing factors, the details about the microelements could be summarized in one or two sentences in consideration of the average reader's knowledge in this area.

\section{B. Sample Text 2}

茅台酒是世界三大名酒之一, 是我国大曲酱香型酒的鼻祖, 是酿 造者以神奇的智慧, 提高粱之精, 取小麦之魂, 采天地之灵气, 捕捉 特殊环境里不可替代的微生物发酵、揉合、升华而笋起的酒文化丰 碑。(1) 茅台酒源远流长, 据史载, 早在公元前 135 年, 古属地茅台 镇就酿出了使汉武帝”甘美之”的枸酱酒，盛名于世。(2)

1915 年，茅台酒荣获巴拿马万国博览会金奖，享誉全球。(3) 建 国后先后荣获国际金奖。畅销 100 多个国家和地区。(4) 茅台酒的生 产工艺古老而独特, 它继承了古代酿造工艺的精华, 闪㷧着现代科技 的光彩 (5) $\mathrm{tml})$

(Source:http://www.moutaichina.com/products/product.h

Moutai is one of the world's 3 most famous liquors. It is the originator in yeast sauce liquor in our country. It is the monument of liquor culture that brewers have used magic talent, distilled the cream of broomcorn, picked up the soul of wheat, exploited the nimbus of the sky and earth, and captured irreplaceable microorganisms of special environment for fermentation, mixing and sublimation. Moutai has a long history. As recorded in history, as early as in 135 BC, Moutai Town, the ancient apanage, brewed the medlar sauce wine that Emperor Wudi of the Han Dynasty had high opinion of, and was thus known throughout the world. In 1915, Moutai won the gold price of Panama Word's Fair, and became known throughout the world.

After the establishment of our country, Moutai has won international gold prizes for several times. It is sold to over 100 countries and regions. The production technique of Moutai is ancient and unique. It inherits the essence of ancient brewery technique, and shines with the color of modern science and technology. t.html)

(Source:http://www.moutaichina.com/en/products/produc

1) Translation criticism: It is quite easy to notice that the translation was done word for word, sentence for sentence. No information seems to be missing, but it does not always make a good rendering because the target receiver is considered important in selecting the information needed for the intended communicative purpose in the target text. The most obvious error the translator has committed is the lack of the target reader orientation, which should have guided the translator with regard to choosing the information or reorganizing the structure.

As previously discovered in both the Chinese and English product introductions of alcoholic drinks, the lexis doubtlessly plays a vital part in imparting the information to the reader and accordingly the lexis in the target text is a make-or-break thing in absorbing fully what the original is trying to deliver.

a) Lexis that does not deliver correctly or fully the information: The necessary information should be correctly and fully conveyed to the reader of the product introduction of an alcoholic drink, but the translator of Text 2 is observed to cram the information into the target language because he seems to dread losing a bit of it, as is shown in the effort he makes to translate word for word and sentence by sentence, and not to have an inkling of what counts as a useful and effective part of it that conforms to the culturally cultivated expectations of the target language reader. Briefly, the translator does not seem to take heed to the cultural differences that may obstruct the imparting of the useful and effective information. The following is to exemplify the distortion of information as a result of the lack of the reader orientation concerning the informative words.

The source text, the Chinese product introduction of Moutai, is intended for the native Chinese when such expressions as “我国 ("in our country”, referring to China; see Sentence 1) are used. However, in the target text it might be a little confusing to put “我国” into "in our country" for the target reader who may happen to have no idea about where the product comes from. Similarly another error can be found in the third paragraph where the Chinese version goes like" 建国后 (“after the founding of the People's Republic of China in 1949"; see Sentence 4)". Although for the source text reader the knowledge of the founding of the republic is something taken for granted, the simplified rendering "after the establishment of our country" barely suffices in terms of providing the target text reader with the information needed for understanding the meaning.

Several translation errors in terms of breaching the linguistic norms or conventions of the target language can be detected (Sentence 2\&3), including misuse of words and a spelling mistake.

Different words (verbs) are used to show how different kinds of alcoholic drinks are produced. The verb "brew" in "brewed the medlar sauce wine......" is mistakenly used, for it means "make beer by mixing, boiling and fermenting malt, 
hops, etc. and water", when it refers to making alcoholic drinks. According to the ingredients needed and the special production process or technique, making medlar sauce wine is better expressed as fermenting or fermentation, which means "make something change chemically through the action of organic substances (esp. yeast)"1. Accordingly, neither the word "brewed", nor the noun referring to the producer of the liquor (brewers) in the previous paragraph is well chosen.

Another translation error could have been avoided if the translator had paid a little more attention to the spelling of words. Unfortunately “巴拿马万国博览会 (The 1915 Panama Pacific International Exposition)" was turned into "Panama Word's Fair", which should at least have been "Panama World's Fair"'

In the same paragraph still another translation problem is worth discussing: the phrase "known throughout the world". After reading through the paragraph in question, the reader will notice a repetition of this expression. It is correct in itself, but the first use of the phrase seems inappropriate in the given context. The whole sentence is about the history of Moutai, which traces back to Han Dynasty. The central idea of the retrospect is making the point that the wine had been well known throughout the country thanks to the fact that Emperor Wudi liked it. Nevertheless, it is not likely that the wine was worldwide famous back then. Additionally, the next sentence is focusing on the world-renowned reputation of Moutai thanks to The 1915 Panama Pacific International Exposition. Obviously the two sentences are intended originally to reveal the progress Moutai is making and thus the first use of "throughout the world" is nothing but the distortion of the information to be conveyed to the target reader.

Last but not least, many problems lie with the use of words that add to aesthetic value and that serve as proud boast. As discussed in the previous chapter, though adding to the aesthetic value of the Chinese text, Sentence 1 is no more than one imparting the information about the ingredients: “高 梁(sorghum)”, “小麦(wheat)”and “微生物(microorganism)”. However, the translator goes so far as to have had the lexis (“cream” for “精”, “soul” for “魂” and “nimbus” for “灵气”) reproduced in the English version, the result being that the information may have been covered in the target text by a group of words that may add to the aesthetic value of the source text and that, however, may make a square peg in a round hole owing to the culturally and hence aesthetically different expectations of the target text reader.

Likewise, most of the words that serve as the proud boast are kept in the translation, some being necessary and some redundant. The sender of the source text identifies the liquor as one of the most famous liquors in the world and the ancestor of yeast sauce liquor in China, which may be accepted as appropriate and attractive as an opening remark in the English product introduction of an alcoholic drink. The following cases may deserve criticism either for the unnecessary or poor transference of information into English. While providing the information about the ingredients (See Sentence 1), the sender first of all shows “酿造者以神奇的智慧 (the remarkable wisdom of the liquor makers)" as if wisdom were one of the critical ingredients needed; on the other hand the phrase is rendered as "brewers have used magic talent" in English. Another use of words as proud boast, which may be thought of as a case of sheer exaggeration, lies in “酒文化丰碑 (a milestone in the history of the liquor culture)", while the translator uses "a monument to the liquor culture" for the target reader.

Strictly speaking, some words can be regarded as belonging to two categories (of the three categories analyzed in the sample texts) at the same time, because in this piece of introduction, some words that add to the aesthetic value can serve as proud boast as well. The most typical ones are : “精” (cream), “魂” (soul) and “灵气” (nimbus; see Sentence 1); “精 华” (essence) and “光彩” (colour; see Sentence 5). Those words work perfectly in Chinese, but their equivalents in English are more redundant and confusing than necessary or helpful because, as stated above, the things those equivalent words refer to are mostly not what the native speaker of English is expected to feel at ease about, not at least when he is exposed to such things as the introduction of an alcoholic drink.

All the translation errors above point to the failure to take into account the cultural differences by overriding the expectations of the target readers, socially and culturally cultivated, and the failure to correctly convey the information to the target reader. All those will presumably reduce the appealing force of the introduction of the drink because they are observed to affect, if not block, the communication between the sender and the reader.

a) Sentences that rigidly follow the structures of the original: The above analysis of the translation and the Chinese product introduction indicates that the source text originally aims at the customer at home, but the target reader will probably be confused by and puzzled about the reproduction of the balanced sentence or clause structures in Chinese.

In Chinese, a balanced structure is usually preferred, which usually is framed in coordinate clauses or in the form of parallelism. A typical case in point is the sentence explaining the ingredients of the liquor (See Sentence 1). The English translation even copies the exact sentence structure of the original ("distilled the cream of broomcorn”[提高梁之精], “picked up the soul of wheat” [取小 麦之魂], “exploited the nimbus of the sky and earth” [采天地 之灵气]). The three coordinate clauses are supposed to appeal to the Chinese reader with the beautifully balanced structure, all in a form of "verb + object (a phrase)". The intention of the translator is to achieve the same aesthetic value the Chinese original can by framing the clauses in a chain of verbs (distilled, picked up, exploited, captured), the result being a run-on sentence in English. As already covered in the previous section about the use of lexis, the focus of each clause does not literally lie with the three words “精”, “魂” and “灵气”, so the rigid literal translation in the form of "verb (distill, pick up/exploit) + object (the cream of the broomcorn/the soul of wheat/the nimbus of the sky and 
earth)" does not really make much sense to the target reader who may be lost in the exaggerated figures of speech (comparing the ingredients to human beings by endowing them spirits or souls). Sentence 1 in Chinese is featured in a “...是 (is) …" sentence pattern, which brings out several clauses that comprise a long sentence, but the English version would not have to follow suit using the same sentence pattern. The whole sentence could have been broken into several parts (parts of identity and ingredients, for example). Practically it would be easier and more effective for the target reader to get the idea if the translator just brushed aside the structure of the original sentence and conveyed the necessary information in a concise way: The main ingredients include selected sorghum and wheat, which are fermented with the irreplaceable microorganism.

As the new audience, the target reader has different expectations and previous knowledge of the information the target text is going to deliver as well as of the form in which it is conveyed. What a good translator does is to offer the information in another form. At the end of this piece of product introduction (See Sentence 5), the translation is found sticking to its original form, however. In the original, the two clauses go with the same sentence structure, that is, subject (它) + verb (继承了/闪㷧着) + object (古代酿造工艺的精 华/现代科技的光彩). The Chinese reader understands which point to catch in the phrases (the two objects): the ancient method and the modern technology are the point. When the translator puts the clauses this way "It inherits the essence of the ancient brewery technique, and shines with the color of modern science and technology", s/he is apparently restrained by the structures of the two Chinese clauses (verb: inherits + object: essence of the ancient brewery technique) and does not have many thoughts about what the original sentence aims to convey. The sentence structure will more likely strike one as being something foreign to the eye of a native speaker of English, which can hardly make them feel at home. What is more confusing to the target reader may be "the color of modern science and technology", a version of literal translation.

\section{CONCLUSION}

Most of the Chinese samples are found at loss what to focus and how to organize the text when it comes to content and composition. One of the common problems turns out to be that of the lexis in the translation: failing to deliver the messages correctly or fully. The translations are restrained from the sentence structure (long and complex sentences) or sentence function (declarative sentences) of the original, which therefore stand aloof from the reader in terms of the appellative function of the text intended.

Both the intratextual and extratextual factors play a part in the transferring process and the translation brief that specifies the purpose of the translation task suggests proper translation methods. The above discussion indicates and verifies the importance and significance of target receiver orientation. Informative as the product introductions are, their main function is supposed to be "appellative", by which what is meant is appealing to the reader to act in a certain way ( $\mathrm{Li}$ et al, 2005:87), by providing information, persuading the reader to accept and buy the products in particular in the given situation. As Nord (2001:73) puts it: Inadequacy is not a quality inherent in any expression but a quality assigned to the expression from an evaluator's point of view, the target reader, to some extent, judges the translation from his/her angle. Thus it always requires target reader orientation if the intended communicative purpose of the text is to be achieved.

\section{REFERENCES}

[1] Nord, Christiane. Translating as A Purposeful Activity: Functionalist Approaches Explained. Shanghai: Shanghai Foreign Language Education Press. 2001.

[2] Li Heqing, Huang Hao \& Bo, Zhenjie. Methodology of Western Translation Studies: since the 1970s. Beijing: Peking University Press. 2005.

[3] Nord, Christiane. Text Analysis in Translation: Theory, Methodology, and Didactic Application of a Model for Translation-Oriented Text Analysis. Beijing: Foreign Language Teaching and Research Press. 2006.

[4] Liu Jiafeng. A study of advertisements of Chinese distilled spirits. China Wine. 2002

[5] Ping Hong .Functional typology and translation strategies. Chinese Translations Journal, 23(5), 19-23. 2002.

[6] Yan Jing \& Zhang, Chengping. Research on advertisement translation from the anle of teleology. Journal of Hunan Radio and Television University, 66-67,70. 2006.

[7] Zou Jianling. On Chinese-English translation of product introduction. China Science \& Technology Translation Journal. 2012 